\title{
Bartın (Kocaırmak) Nehir Yatağının Taşkın Kapasitenin Belirlenmesi
}

\author{
${ }^{1}$ Emrah Doğan ${ }^{2}$ Tülay Ekemen Keskin ${ }^{1}$ Osman Sönmez ${ }^{3}$ Pınar Spor ${ }^{2}$ Hatice Betül Umarusman and ${ }^{*}$ Meisam Badfar \\ ${ }^{1}$ Faculty of Engineering, Department of Civil Engineering Sakarya University, Turkey \\ ${ }^{2}$ Faculty of Engineering, Department of Civil Engineering Karabuk University, Turkey \\ ${ }^{3}$ Faculty of Engineering, Department of Geological Engineering Bülent Ecevit University, Turkey \\ ${ }^{*} \mathrm{Ph}$.D. candidate, Faculty of Engineering, Department of Civil Engineering Sakarya University, Turkey
}

\section{Özet}

Taşkınlar maddi-manevi kayıpların yanı sıra can kayıplarına da neden olan doğal afetlerin başında gelmektedir. Türkiye'de nüfus artışı ile birlikte yeraltı ve yerüstü su kaynaklarının bilinçsiz kullanımı, ayrıca jeolojik yapı, coğrafi konum ve iklim değişikliğine bağlı olarak küresel ısınmalar da taşkın olaylarının sıklıkla yaşanmasına neden olabilmektedir. Bartın Nehri (Kocaırmak)'nin bulunduğu Batı Karadeniz Havzası her mevsim yağış alan ve yağışların etkisiyle taşkınların meydana geldiği bir bölgedir. Bu çalışmada Bartın Nehri'nin 38 yıllık akım verilerine dayanarak gelmesi muhtemel taşkın debileri Normal, Gumbel, Log Normal ve Pearson istatistiksel yöntemleri kullanılarak hesaplanmıştır. Ek olarak 9 enkesitin gelebilecek taşkınları taşıma kapasiteleri de incelenmiştir. Sonuçta Bartın Nehir yatağının istatistiksel yöntemlerle hesaplanan gelmesi muhtemel debileri taşıyamayacağı görülmüştür.

Anahtar Kelimeler: Doğal Afet, Taşkın, Taşkın Analizi, Barıın (Kocaırmak) Nehri

\section{Determination Of Bartın (Kocairmak) River Flood Capacity}

Floods are one of the natural disasters that cause loss of life as well as material-spiritual losses. Injudicious use of surface and underground water sources, the population growth in Turkey, geological structure, geographical location and global warming due to climatic changes may cause the commonly flood event. The Western Black Sea Basin, where the Bartin (Kocarmak) River is located, is a region where rainfall is observed in every season and floods occur due to precipitation. In this study, the flood discharge of the Bartın River was calculated by using the Normal, Gumbel, Log Normal and Pearson statistical methods. In addition, the carrying capacity of the floods of 9 cross sections was investigated. As a result, it was seen that the Bartın River bed could not carry the probable flood discharge calculated by statistical methods.

Key words: Natural Disaster, Flood, Flood Analysis, Asi River.

\section{Giriş}

Akarsulardaki su seviyesi ve dolayısıyla debi kar erimesi, yağışlar, baraj ve seddelerin yıkılması gibi nedenlere bağlı olarak zamanla gelişigüzel bir şekilde daima değişiklikler göstermektedir. $\mathrm{Bu}$ tür olaylar ise taşkınları beraberinde getirmektedir. Taşkınlar, insan hayatını maddi manevi anlamda etkilediği için büyük önlemler alınarak kontrol altına alınması gerekmektedir [1].

Akarsulardaki akarsu yatak kapasitesinin aşılması sonucu olarak taşkın debileri tarım bölgeleri ve yerleşim yerlerini sular altında bırakarak hasarlara, yapıların yıkılmasına ve dolayısıyla can

*Corresponding author: Address: Faculty of Engineering, Department of Geological Engineering Bülent Ecevit University, 67100, Zonguldak TURKEY. E-mail address: kucuk.pinar@beun.edu.tr, Phone: +903722511858 
kayıplarına sebep olmasından ötürü gelmesi muhtemel taşkın debilerinin hassas bir şekilde hesaplanması büyük önem arz etmektedir [2].

Türkiye bulunduğu enlem-boylam ve jeolojik yapısı nedeniyle maddi ve manevi kaybı en yüksek doğal afetlerin başında gelen taşkınların çok sık yaşandığı ülkelerden biridir. Akarsuların akış rejiminin düzensiz halde olmasından dolayı yaşanan taşkın olayı depremden sonra en fazla can ve mal kaybına sebep olan doğal afettir. Son 20 yılda Türkiye'de 396 insan yaşamını yitirmiş ve ekonomik kayıp yaklaşık olarak 2,5 milyar TL'dir [3].

$\mathrm{Bu}$ çalışmanın amacı Bartın Havzasında bulunan E13A031 numaralı akım gözlem istasyonları tarafından ölçülen 1970-2016 yılları arasındaki ölçüm yapıldıkça elde dilen veriler ile Yıllık Maksimum Feyezan Akımları kullanılarak farklı tekerrür yıllarına göre taşkın hesabı yapılmıştır. Bölgeye ait enkesitler ile nehrin emniyetli geçirebileceği debi hesaplanmış ve hidrolojide yaygın olarak kullanılan istatistiksel yöntemler yardımıyla hesaplanan olası beklenen taşkınlarla karşılaştırılmıştır. Taşkın dönüş aralılarında enkesitlerin emniyetli veya risk altında olup olmadığı incelenmiştir.

Bartın Irmağı havzasında bulunan 9 enkesit bu çalışma kapsamında kullanılmıştır. Enkesitler sayesinde boy kesit ve nehir taban eğimleri bulunmuştur. Bulunan bu eğim sayesinde enkesitlerin emniyetli geçirebilecekleri debiler hesaplanarak hidrolojide sıklıkla kullanılan 4 farklı istatistiksel yöntemlerle hesaplanmış gelmesi muhtemel debiler ile karşılaştırılmıştır. Bu sayede hangi taşkın tekerrür aralığında hangi enkesitlerin emniyetli ve hangilerinin risk altında olduğu incelenmiştir. Sonuçlar bölümünde ise alınması gereken önlemler anlatılmıştır.

\section{Bartın Nehri Havzasının Coğrafi Konumu}

Bartın, Karadeniz Bölgesi'nin Batı Karadeniz Bölümü’nde 3205'58" ile 3255'46" doğu boylamı, $41^{\circ} 18^{\prime 2} 26^{\prime \prime}$ ile 4150'53" kuzey enlemi üzerinde bir ildir. İlin doğusunda Kastamonu, batısında Zonguldak, güneyinde Karabük ili ve kuzeyinde Karadeniz bulunur [4].

Bartın Irmağı Havzası DSİ'nin 13 Nolu Batı Karadeniz Su Havzası'nda bulunmakta ve yaklaşık $2100 \mathrm{~km}^{2}$ drenaj alanıyla birlikte Filyos Çayı Havzası'ndan sonra bölgenin en büyük akarsu havzasıdır. Bartın Irmağı Havzası'nın büyük bir bölümü Bartın ili sınırlarında diğer bölümleri de Kastamonu, Karabük ve Zonguldak illerinin sınırları içerisinde bulunmaktadır. Bartın Irmağı Havzası'nın komşuları kuzeyde Amasra ilçesi, güneydoğuda Eflani ve Safranbolu ilçeleriyle, güney ve batıda da ise Filyos Çayı Havzası'dır [5].

Bartın Irmağının membası Karabük ve Kastamonu illerindeki Ilgaz Dağları olup, kuzeye doğru akar. Bartın şehir merkezi, Gazhane Burnundaki Kocaçay ve Kocanaz çaylarıının birleşerek oluşturduğu 1rmağın döküldüğü yer ise yaklaşık 15 km'den sonra Karadeniz'in Boğaz Mevkiisidir. Bu çalışmada E13A031 numaralı Kocaırmak-Bartın istasyonundan alınan anlık maksimum akımlar ile gelmesi muhtemel taşkın debileri hesaplanarak nehir yatağın taşıma kapasitesi irdelenmiştir. 


\section{Materyal ve Yöntem}

Çalışma alanında bulunan E13A031 numaralı istasyona ait veriler kullanılarak 1970-2016 yılları arası dönem için debi süreklilik çizgisi Şekil 1'de verilmiştir.

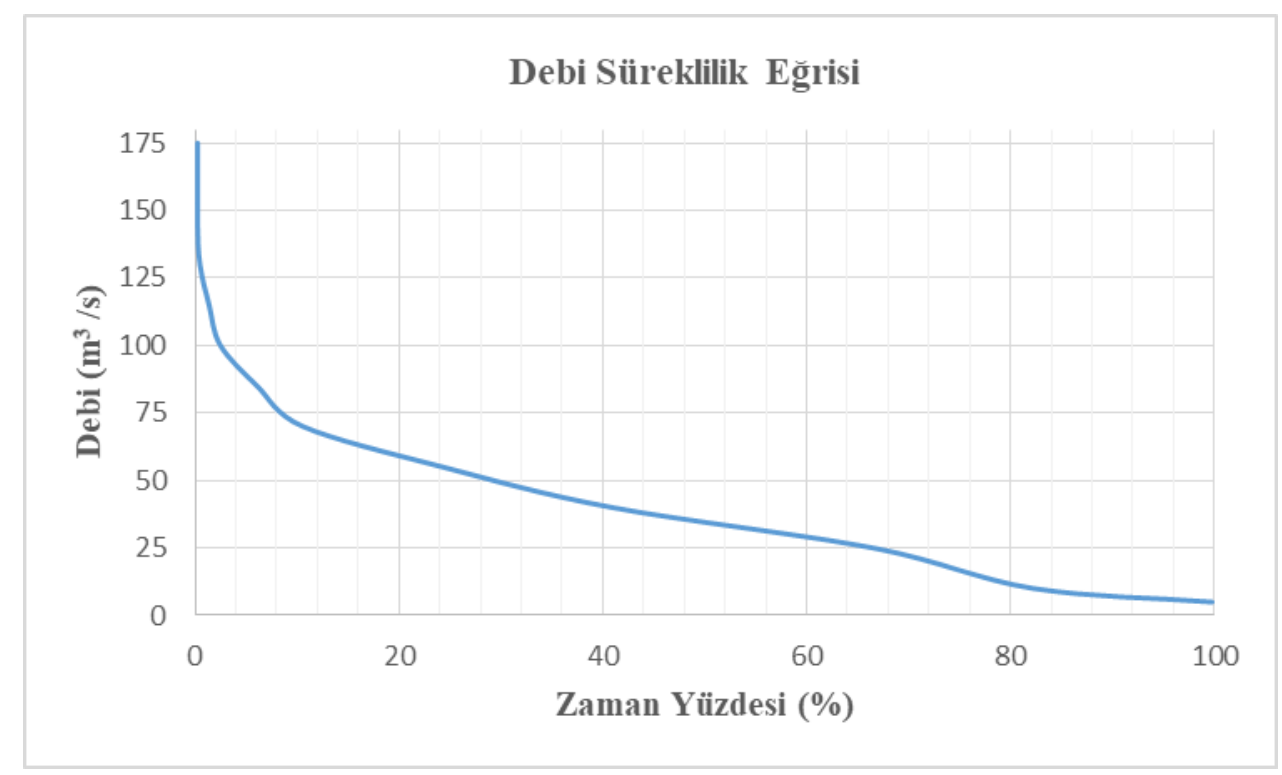

Şekil 1. E13A031 numaralı istasyona ait Debi Süreklilik Çizgisi.

Hidrolojide s1klıkla kullanılan istatistiksel yöntemler ile E13A031 numaralı istasyona ait maksimum anlık feyezan verilerinden yararlanarak:

Normal dağılım fonsiyonu ile yapılan hesaplama sonucunda 2, 5, 10, 25, 50, 100, 200, 500 ve 1000 yıllık tekerrürlere göre sırasıyla 460.24, 649.36, 749.21, 856.43, 925.66, 987.38, 1042.93, 1108.38 ve $1152.62 \mathrm{~m}^{3} / \mathrm{s}$ taşkın debisi gelmesi beklenmektedir.

Gumbel dağılım fonsiyonu ile yapılan hesaplama sonucunda 2, 5, 10, 25, 50, 100, 200, 500 ve 1000 yıllık tekerrürlere göre sirasıyla 305.49, 713.62, 983.83, 1325.25, 1578.53, 1829.95, 2080.44, 2410.92 ve $2660.69 \mathrm{~m}^{3} / \mathrm{s}$ taşkın debisi geleceği öngörülmüştür.

Log Normal dağılım fonsiyonu ile yapılan analiz sonucunda 2, 5, 10, 25, 50, 100, 200, 500 ve 1000 yıllık tekerrürlere göre sirasıyla 410.54, 618.54, 768.79, 970.29, 1127.63, 1289.31, 1454.59, 1676.65 ve $1845.66 \mathrm{~m}^{3} / \mathrm{s}$ taşkın debisi geleceği öngörülmüştür.

Pearson dağılım fonsiyonu ile yapılan hesaplamalar sonucunda 2, 5, 10, 25, 50, 100, 200, 500 ve 1000 yıllık tekerrürlere göre sirasiyla 428.25, 632.94, 761.05, 915.24, 1024.40, 1128.36, 1237.44, 1351.05 ve $1438.94 \mathrm{~m}^{3} / \mathrm{s}$ taşkın debisi geleceği öngörülmüştür. 


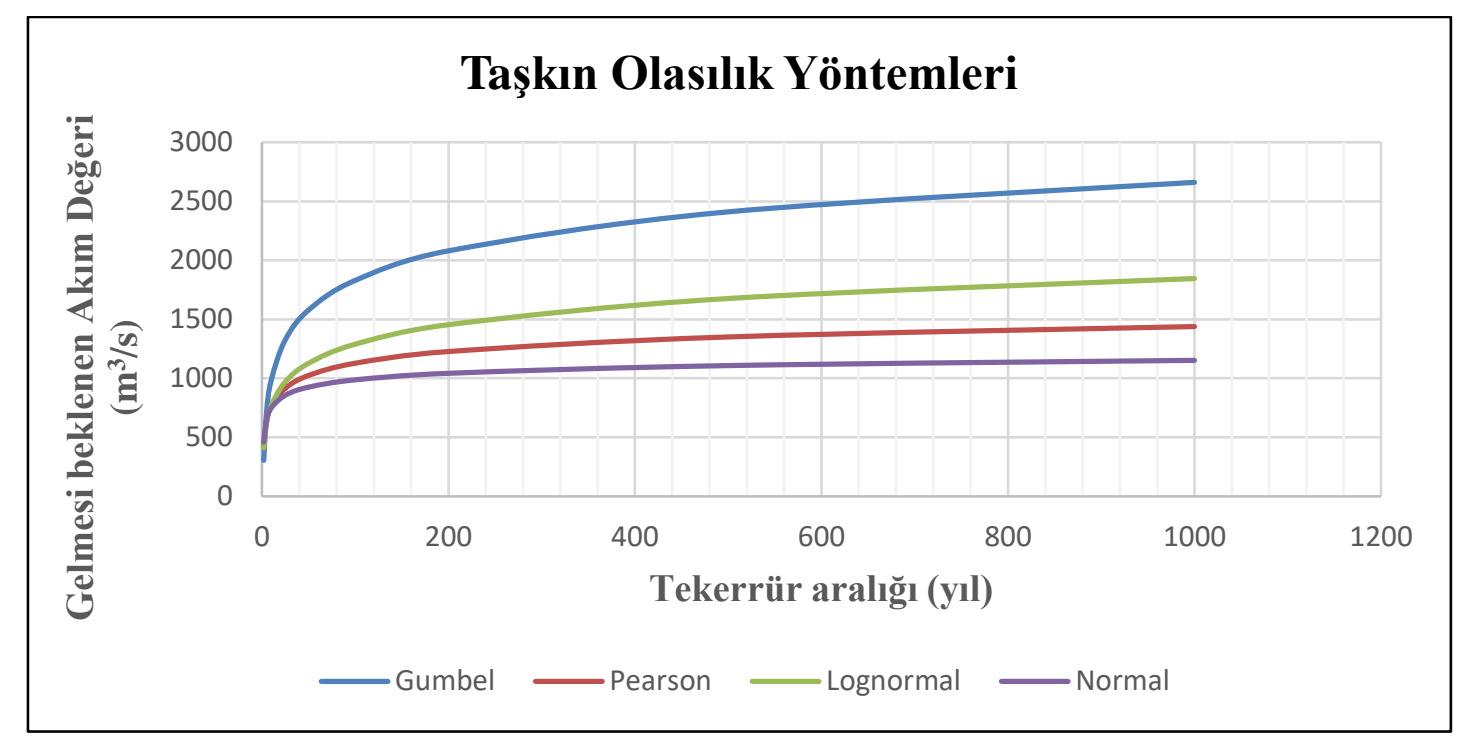

Şekil 2. E13A031 numaralı istasyona ait farklı yöntemlerle hesaplanan gelmesi muhtemel taşkın debileri.

\section{Nehir Geçirebileceği Emniyetli Tekerrürlü Taşkın Debilerinin Belirlenmesi}

Taşkın debileri hidrolojide yaygın olarak kullanılan Normal, Log Normal, Gumbel ve Pearson dağılımlarına göre bulunmuştur. Normal Dağılım aşağıdaki gibi verilir [6],[7],[8],[9].

$f(x)=\frac{1}{\sigma \sqrt{2 \pi}} \exp \left(-\frac{(x-\mu)^{2}}{2 \sigma^{2}}\right) \quad-\infty \leq x \leq \infty$

Burada,

$\mu=\bar{x}=$ aritmetik ortalama, $\sigma=s_{x}=$ standart sapmadır.

Belirli dönüş (tekerrür) aralıları (T) için beklenen olası (muhtemel) taşkınlar aşağıda verilen denklem yardımıla hesaplanabilir.

$x_{T}=\mu+\Delta x_{T}$

Burada:

$x_{T}=\mathrm{T}$ dönüş aralığında beklenen olası taşkın miktarı,

$\mu=$ Gözlenen maksimum anlı feyezan akımları (MAFA) değerlerinin ortalaması,

$\Delta x_{T}=$ Ortalamadan sapmayı veya değişimi ifade eden miktardır ve $\Delta x_{T}=K_{T} \sigma$ olarak yazılabilir.

Buna göre yukarıdaki denklem aşağıdaki gibi tekrar yazılabilir.

$x_{T}=\mu+K_{T} \sigma$ 
Burada,

$K_{T}=$ Frekans faktörü,

$\sigma=$ Standart sapmadır.

Normal dağılım için $K_{T}$ aşağıdaki gibi hesaplanabilir.

$K_{T}=w-\frac{2.515517+0.802853 w+0.010328 w^{2}}{1+1.432788 w+0.189269 w^{2}+0.001308 w^{3}}$

Burada w aşağıdaki gibi hesaplanabilir.

$w=\left[\ln \left(\frac{1}{p^{2}}\right)\right]^{1 / 2} \quad(0<p \leq 0.5)$

Burada $\mathrm{p}$ dönüş aralığının aşılma olasılığıdır ve $p=\frac{1}{T}$ denklemiyle hesaplanır.

Her bir dönüş aralığı için (3), (4) ve (5) denklemleri kullanılarak Normal dağılıma göre beklenen olası taşkınlar hesap edilir.

Log Normal dağılım ise aşağıdaki gibi verilir.

$f(x)=\frac{1}{x \sigma \sqrt{2 \pi}} \exp \left(-\frac{\left(y-\mu_{y}\right)^{2}}{2 \sigma_{y}^{2}}\right) \quad x>0$

Burada,

$y=\log x \quad \mu_{y}=\bar{y} \sigma_{y}=s_{y}$

Log-Normal Dağılım için gözlenen MAFA değerleri $\mathrm{y}=\log (\mathrm{x})$ ile dönüştürülerek ve yukarıdaki aynı denklemler $(3,4,5)$ kullanılarak beklenen olası taşkınlar hesaplanır.

Gumbel (Ekstrem Değer) dağılım için aşağıdaki gibidir.

$f(x)=\frac{1}{a} \exp \left[-\frac{(x-u)^{2}}{a}-\exp \left(-\frac{x-u}{a}\right)\right]-\infty<x<\infty$

Burada,

$a=\frac{\sqrt{6} s_{x}}{\pi} \quad u=\bar{x}-0.5772 a$

Gumbel dağılımı için (3) denklemindeki $K_{T}$ değeri aşağıdaki denklem yardımıyla hesaplanabilir.

$K_{T}=-\frac{\sqrt{6}}{\pi}\left\{0.5772+\ln \left[\ln \left(\frac{T}{T-1}\right)\right]\right\}$

Pearson Dağılımı için formül aşağıdaki gibi verilir: 
$f(x)=|\beta|\left[\beta(x-\varepsilon]^{a-1} \frac{\exp [-\beta(x-\varepsilon)]}{\Gamma(a)}\right.$

Dağılımın a, biçim, $\beta$ ölçek ve $\varepsilon$ yer parametresidir. $a>0, \beta>0$ için $x>\varepsilon$ olup $\varepsilon$ alt sınırı oluşturur. $\beta<0$ içinse $x<\varepsilon$ olup üst sınırdır.

$x<\varepsilon$ için $C_{s x}=\frac{2}{\sqrt{a}}$ ve $x>\varepsilon$ için $C_{s x}=\frac{-2}{\sqrt{a}}$ olur.

Ayrıca $\beta>0$ ve $\varepsilon=0$ için $C_{s x}=2 C V_{x}$ olup dağılım Gamma dağılımına indirgenir [1].

Bu çalışmada Bartın Nehir üzerinden alınan 9 enkesitin gelebilecek olası taşkın debilerinin taşıma kapasiteleri hesaplanmıştır. Bartın Nehri E13A031nolu akım gözlem istasyonunda elde edilen Maksimum Anlık Feyezan Akımları (MAFA) kullanılmıştır. MAFA değerleri kullanılarak farklı dönüş aralıkları (tekerrür periyotları) için Normal, Gumbel, Log Normal ve Pearson dağılım fonksiyonları ile hesaplanan beklenen olası taşkınlar, kesitin taşıma kapasitesi ile kıyaslanmıştır.

En kesitin taşkın kapasitesi Manning formülü ile hesaplanmıştır. Manning pürüzlülük katsayısının (n) 0.0051 alınabileceği öngörülmüştür.

$Q=\frac{1}{n} R^{2 / 3} J^{1 / 2} A$

Burada, Q;debi (m³/sn), n;manning pürüzlülük katsayısını, R; hidrolik yarıçapı, J; kanal taban eğimini ve A; enkesit alanını ifade etmektedir.

Tablo1. Bartın Nehrinden Alınan Enkesitlerin Özellikleri

\begin{tabular}{|c|l|c|c|c|c|c|c|}
\hline Kesit No & $\begin{array}{c}\text { Uzaklık } \\
(\mathbf{k m})\end{array}$ & $\begin{array}{c}\text { Enkesit } \\
\text { Alanı } \\
\left(\mathbf{m}^{\mathbf{2}} \mathbf{)}\right.\end{array}$ & $\begin{array}{c}\text { Islak } \\
\mathbf{C C e v r e} \\
(\mathbf{m})\end{array}$ & $\begin{array}{c}\text { Hidrolik } \\
\text { Yarıçap } \\
(\mathbf{m})\end{array}$ & $\mathbf{E} \mathbf{\text { ğim j j }}$ & $\mathbf{n}$ & $\begin{array}{c}\text { Debi (Q) } \\
\left(\mathbf{m}^{\mathbf{3}} / \mathbf{s}\right)\end{array}$ \\
\hline 1 & $13+762.605$ & 539.37 & 117.47 & 4.59 & 0.001 & 0.051 & 925.92 \\
\hline 2 & $12+108.972$ & 497.09 & 123.48 & 4.03 & 0.0029 & 0.051 & 1336.27 \\
\hline 3 & $12+867.201$ & 680.99 & 155.82 & 4.37 & 0.0011 & 0.051 & 1183.78 \\
\hline 4 & $8+127.646$ & 722.02 & 165.76 & 4.36 & 0.0014 & 0.051 & 1412.83 \\
\hline 5 & $11+606.455$ & 610.99 & 110.76 & 5.52 & 0.0011 & 0.051 & 1240.5 \\
\hline 6 & $4+283.860$ & 526.29 & 1188.91 & 0.44 & 0.0012 & 0.051 & 207.64 \\
\hline 7 & $6+069.032$ & 715.74 & 182.67 & 3.92 & 0.0015 & 0.051 & 1350.87 \\
\hline 8 & $0+503.361$ & 578.86 & 147.76 & 3.92 & 0.0018 & 0.051 & 1196.71 \\
\hline 9 & $2+062.489$ & 455.74 & 94.89 & 4.80 & 0.0023 & 0.051 & 1219.91 \\
\hline
\end{tabular}


Tablo 2. Kesitlerin Taşıyabileceği Debilerin Normal Dağılım Yöntemine Göre Beklenen Taşkınlarla Karşılaştırılması

\begin{tabular}{|c|c|c|c|c|c|c|c|c|c|}
\hline En Kesit & Debi $\left(\mathbf{m}^{\mathbf{3}} / \mathbf{s}\right)$ & \multicolumn{8}{|c|}{ Beklenen Taşkın Debileri } \\
\hline & & $\mathbf{5}$ & $\mathbf{1 0}$ & $\mathbf{2 5}$ & $\mathbf{5 0}$ & $\mathbf{1 0 0}$ & $\mathbf{2 0 0}$ & $\mathbf{5 0 0}$ & $\mathbf{1 0 0 0}$ \\
\hline 1 & 925.95 & 649.36 & 749.21 & 856.43 & 925.66 & 987.38 & 1042.93 & 1108.38 & 1152.62 \\
\hline 2 & 1336.63 & 649.36 & 749.21 & 856.43 & 925.66 & 987.38 & 1042.93 & 1108.38 & 1152.62 \\
\hline 3 & 1164.15 & 649.36 & 749.21 & 856.43 & 925.66 & 987.38 & 1042.93 & 1108.38 & 1152.62 \\
\hline 4 & 1432.26 & 649.36 & 749.21 & 856.43 & 925.66 & 987.38 & 1042.93 & 1108.38 & 1152.62 \\
\hline 5 & 1258.42 & 649.36 & 749.21 & 856.43 & 925.66 & 987.38 & 1042.93 & 1108.38 & 1152.62 \\
\hline 6 & 205.14 & 649.36 & 749.21 & 856.43 & 925.66 & 987.38 & 1042.93 & 1108.38 & 1152.62 \\
\hline 7 & 1355.77 & 649.36 & 749.21 & 856.43 & 925.66 & 987.38 & 1042.93 & 1108.38 & 1152.62 \\
\hline 8 & 1181.15 & 649.36 & 749.21 & 856.43 & 925.66 & 987.38 & 1042.93 & 1108.38 & 1152.62 \\
\hline 9 & 1214.93 & 649.36 & 749.21 & 856.43 & 925.66 & 987.38 & 1042.93 & 1108.38 & 1152.62 \\
\hline
\end{tabular}

Tablo 3. Kesitlerin Taşıyabileceği Debilerin Gumbel Yöntemine Göre Beklenen Taşkınlarla Karşılaştırılması

\begin{tabular}{|c|c|c|c|c|c|c|c|c|c|}
\hline En Kesit & Debi $\left(\mathbf{m}^{\mathbf{3}} / \mathbf{s}\right)$ & \multicolumn{8}{|c|}{ Beklenen Taşkın Debileri } \\
\hline & & $\mathbf{5}$ & $\mathbf{1 0}$ & $\mathbf{2 5}$ & $\mathbf{5 0}$ & $\mathbf{1 0 0}$ & $\mathbf{2 0 0}$ & $\mathbf{5 0 0}$ & $\mathbf{1 0 0 0}$ \\
\hline 1 & 925.95 & 713.62 & 983.83 & 1325.25 & 1578.53 & 1829.95 & 2080.44 & 2410.92 & 2660.69 \\
\hline 2 & 1336.63 & 713.62 & 983.83 & 1325.25 & 1578.53 & 1829.95 & 2080.44 & 2410.92 & 2660.69 \\
\hline 3 & 1164.15 & 713.62 & 983.83 & 1325.25 & 1578.53 & 1829.95 & 2080.44 & 2410.92 & 2660.69 \\
\hline 4 & 1432.26 & 713.62 & 983.83 & 1325.25 & 1578.53 & 1829.95 & 2080.44 & 2410.92 & 2660.69 \\
\hline 5 & 1258.42 & 713.62 & 983.83 & 1325.25 & 1578.53 & 1829.95 & 2080.44 & 2410.92 & 2660.69 \\
\hline 6 & 205.14 & 713.62 & 983.83 & 1325.25 & 1578.53 & 1829.95 & 2080.44 & 2410.92 & 2660.69 \\
\hline 7 & 1355.77 & 713.62 & 983.83 & 1325.25 & 1578.53 & 1829.95 & 2080.44 & 2410.92 & 2660.69 \\
\hline 8 & 1181.15 & 713.62 & 983.83 & 1325.25 & 1578.53 & 1829.95 & 2080.44 & 2410.92 & 2660.69 \\
\hline 9 & 1214.93 & 713.62 & 983.83 & 1325.25 & 1578.53 & 1829.95 & 2080.44 & 2410.92 & 2660.69 \\
\hline
\end{tabular}

Tablo 4. Kesitlerin Taşıyabileceği Debilerin Log-Normal Yöntemine Göre Beklenen Taşkınlarla Karşılaştırılması

\begin{tabular}{|c|c|c|c|c|c|c|c|c|c|}
\hline \multirow[t]{2}{*}{ En Kesit } & \multirow[t]{2}{*}{ Debi $\left(\mathrm{m}^{3} / \mathrm{s}\right)$} & \multicolumn{8}{|c|}{ Beklenen Taşkın Debileri } \\
\hline & & 5 & 10 & 25 & 50 & 100 & 200 & 500 & 1000 \\
\hline 1 & 925.95 & 618.54 & 768.79 & 970.29 & 1127.63 & 1289.31 & 1454.59 & 1676.65 & 1845.66 \\
\hline 2 & 1336.63 & 618.54 & 768.79 & 970.29 & 1127.63 & 1289.31 & 1454.59 & 1676.65 & 1845.66 \\
\hline 3 & 1164.15 & 618.54 & 768.79 & 970.29 & 1127.63 & 1289.31 & 1454.59 & 1676.65 & 1845.66 \\
\hline 4 & 1432.26 & 618.54 & 768.79 & 970.29 & 1127.63 & 1289.31 & 1454.59 & 1676.65 & 1845.66 \\
\hline 5 & 1258.42 & 618.54 & 768.79 & 970.29 & 1127.63 & 1289.31 & 1454.59 & 1676.65 & 1845.66 \\
\hline 6 & 205.14 & 618.54 & 768.79 & 970.29 & 1127.63 & 1289.31 & 1454.59 & 1676.65 & 1845.66 \\
\hline 7 & 1355.77 & 618.54 & 768.79 & 970.29 & 1127.63 & 1289.31 & 1454.59 & 1676.65 & 1845.66 \\
\hline 8 & 1181.15 & 618.54 & 768.79 & 970.29 & 1127.63 & 1289.31 & 1454.59 & 1676.65 & 1845.66 \\
\hline 9 & 1214.93 & 618.54 & 768.79 & 970.29 & 1127.63 & 1289.31 & 1454.59 & 1676.65 & 1845.66 \\
\hline
\end{tabular}


Tablo 5. Kesitlerin Taşıyabileceği Debilerin Pearson Yöntemine Göre Beklenen Taşkınlarla Karşılaştırılması

\begin{tabular}{|c|c|c|c|c|c|c|c|c|c|}
\hline \multirow[t]{2}{*}{ En Kesit } & \multirow[t]{2}{*}{ Debi $\left(\mathrm{m}^{3} / \mathrm{s}\right)$} & \multicolumn{8}{|c|}{ Beklenen Taşkın Debileri } \\
\hline & & 5 & 10 & 25 & 50 & 100 & 200 & 500 & 1000 \\
\hline 1 & 925.95 & 632.94 & 761.05 & 915.24 & 1024.40 & 1128.36 & 1237.44 & 1351.05 & 1438.94 \\
\hline 2 & 1336.63 & 632.94 & 761.05 & 915.24 & 1024.40 & 1128.36 & 1237.44 & 1351.05 & 1438.94 \\
\hline 3 & 1164.15 & 632.94 & 761.05 & 915.24 & 1024.40 & 1128.36 & 1237.44 & 1351.05 & 1438.94 \\
\hline 4 & 1432.26 & 632.94 & 761.05 & 915.24 & 1024.40 & 1128.36 & 1237.44 & 1351.05 & 1438.94 \\
\hline 5 & 1258.42 & 632.94 & 761.05 & 915.24 & 1024.40 & 1128.36 & 1237.44 & 1351.05 & 1438.94 \\
\hline 6 & 205.14 & 632.94 & 761.05 & 915.24 & 1024.40 & 1128.36 & 1237.44 & 1351.05 & 1438.94 \\
\hline 7 & 1355.77 & 632.94 & 761.05 & 915.24 & 1024.40 & 1128.36 & 1237.44 & 1351.05 & 1438.94 \\
\hline 8 & 1181.15 & 632.94 & 761.05 & 915.24 & 1024.40 & 1128.36 & 1237.44 & 1351.05 & 1438.94 \\
\hline 9 & 1214.93 & 632.94 & 761.05 & 915.24 & 1024.40 & 1128.36 & 1237.44 & 1351.05 & 1438.94 \\
\hline
\end{tabular}

\section{Sonuç ve Öneriler}

Bartın Irmağı Havzası'nda hayatı zorlaştıracak kadar etki yaratıp büyük mal ve can kayıplarına yol açan doğal afetlerden biride taşkınlardır. Bu çalışma sırasında DSİ'nin E13A031 numaralı akım gözlem istasyona (AGI) ait uzun yıllara dayanan anlık maksimum akım değerleri ve çalışma alanına ait farklı yerlerden alınmış 9 enkesit yardımıyla nehir yatağının taşıyabileceği taşkın kapasitesi araştırılmıştır.

Yapılan hesaplara göre enkesitlerin, çoğunlukla Normal Dağılım fonksiyonu ile hesaplanmış debilerde gelmesi muhtemel taşkınları taşıyabileceği görülmüştür (6. kesit hariç). Gumbel dağılımı hesaplanan debilerle karşılaştırıldığında $1,3,5,8$ ve 9 numaralı enkesitler 25 yıldan sonrasını; 2, 4 ve 7 numaralı enkesitler ise 50 yıldan sonrasını taşıyamayacağı saptanmıştır. Log Normal dağılımı kullanıldığında 2, 4 ve 7 numaralı enkesitler 200 yıllık beklenen debi ve sonrasını;, 3, 5, 8 ve 9 numaralı enkesitler 100 y1l ve sonrasını; 9 numaralı en kesit 50 y1l ve sonrasın1; 1 numaralı enkesit 25 yıl ve sonrasını; ve 6 numaralı enkesit ise 5 yıl ve sonrasına ait debileri taşıyamayacağ 1 ortaya çıkmıştır. Son olarak Pearson dağılımı ile karşılaştırma yapıldığında ise 4 ve 7 numaralı enkesitlerin 1000 yıldan daha büyük debileri; 2 ve 5 numaralı enkesitlerin 500 yıldan daha büyük debileri; 3, 8 ve 9 numaralı enkesitlerin 200 yıldan daha büyük debileri; 1 numaralı enkesitin 50 yıllık debiyi; 6 numaralı enkesitin ise 5 yıldan daha büyük debileri taşıyabileceği belirlenmiştir.

Bu sonuçlara göre özellikle 6 numaralı enkesitin 5 yıllık taşkın debisini dahi karşılayamayacağı ortaya çıkmıştır. Taşkın riski yüksek olan diğer enkesitin ise 1 numaralı enkesit olduğu saptanmıştır ve bu enkesitin de en fazla 100 yıllık debiyi karşılayabileceği görülmüştür. Bu nedenle herhangi bir zamanda yaşanacak taşkın afetinde bu enkesitlerin bulunduğu bölgelerde büyük kayıplar olabileceği öngörülmektedir.

Çalışma alanının taşkınlardan korumak için acilen önlemler alınmalıdır, çünkü enkesitlerin taşkın taşıma kapasiteleri yetersiz kalmaktadır. Bunun için taşkın yatağı 1000 yıl ve daha fazlası taşkınları 
karşılayacak şekilde genişletilmelidir. Bunlara ek olarak nehrin sağ sahil ve sol sahiline seddeler, taşkın duvarları yapılarak önlemler alınabilir.

\section{Teşekkürler}

$\mathrm{Bu}$ çalışmada kullandığımız enkesitler ve maksimum anlık feyezan akım değerlerinin elde edilmesinde yardımlarını esirgemeyen DSİ 23. Bölge Müdürlüğü Havza Yönetimi, İzleme ve Tahsisler Şube Müdürü Sayın Mevlüt Tutar'a, DSİ 23. Bölgede çalışan Jeoloji Mühendisi Sayın Yusuf Yiğit'e teşekkürü bir borç biliriz.

\section{KAYNAKLAR}

[1] Bayazıt M. ve Önsöz B., Taşkın ve Kuraklık Hidrolojisi, Nobel Akademik Yayıncılık; 2008, 259.

[2] Akarsularda Taşkın Öteleme Metotlarının Karşılaştırılması, Hüsnü Demirpençe, Isparta.

[3] Eroğlu, V., Beşinci Dünya Su Formu, Taşkın konferansı, Bildiri kitabı, 19-20 Haziran, 2008 Edirne.

[4] Bartın Valiliği (2017). Bartın İli 2016 Yılı Çevre Durum Raporu. Çevre ve Şehircilik İl Müdürlüğü, Bartın, 124 s.

[5] DSİ (1998) Bartın Projesi Revize Master Plan Raporu, DSİ XXIII. Bölge Müdürlüğü, Kastamonu.

[6] Bedient, P.B. ve Huber W.C., Hydrology and Floodplain Analysis, Addison-Wesley, 1988.

[7] Chow, V.T.,Maidment, D.R., ve Mays, L.W., Applied Hydrology, McGraw-Hill, New-York, USA, 1988.

[8] Linsley, R.K.,Kohler, M.D., ve Paulhus, J.I.H., Hydrology for Engineers, McGraw-Hill, New York, USA, 1988.

[9] McCuen, R..H., Hydrologic Design and Analysis, Prentice Hall, 1998. 